\title{
Anti-Cytokine Activity of Curcumin and Its Binding to a Fragment of A $\mathrm{BPP}$
}

\author{
Victoria V. Sokolik ${ }^{1}$, Pavel A. Karpov ${ }^{2}$, Dariya A. Samofalova ${ }^{2}$, Sergiy M. Shulga ${ }^{2}$ * \\ ${ }^{1}$ Laboratory of Neurophysiology, Immunology and Biochemistry, Institute of Neurology, Psychiatry and Narcology Natinal Academy of \\ Medical Sciences of Ukraine, Kharkiv, Ukraine \\ ${ }^{2}$ Department of Industrial and Food Biotechnology, Institute for Food Biotechnology and Genomics National Academy of Sciences of \\ Ukrainea, Kiev, Ukraine
}

Email address:

Shulga5@i.ua (S. M. Shulga)

${ }^{*}$ Corresponding author

\section{To cite this article:}

Victoria V. Sokolik, Pavel A. Karpov, Dariya A. Samofalova, Sergiy M. Shulga. Anti-Cytokine Activity of Curcumin and Its Binding to a Fragment of AßPP. Advances in Biochemistry. Vol. 4, No. 4, 2016, pp. 34-46. doi: 10.11648/j.ab.20160404.11

Received: May 19, 2016; Accepted: June 2, 2016; Published: June 20, 2016

\begin{abstract}
Since it has been shown that Alzheimer's disease is accompanied by higher peripheral concentrations of cytokines, we focused on the correction of chronic inflammation causing $A \beta$ excess and aggregation what should have a positive impact. Proinflammatory cytokines action is realized by NF- $\mathrm{kB}$ intracellular signals. Curcumin can inhibit activation of the proinflammatory transcription factor NF- $\mathrm{kB}$ and is able to be mounted in the amyloid- $\beta$ fibrils and encourage their disaggregation. To study the influence of anti-inflammatory effect of curcumin and its ability to model complexes with a fragment of A $\beta$ PP. Investigation was carried out on rats with model of Alzheimer's disease using nasal therapy with curcumin Concentration of cytokines in cerebral cortex, hippocampus and blood serum, and indicators of conditioned active escape reflex were determined in this study. Methods of molecular dynamics and docking were used to examine the interactions of curcumin with fragment of A $\beta$ PP. A $\beta 42$ _Human in the hippocampus of rats provoked chronic neuroinflammation specifically and primarily at the injection site. Curcumin performance revealed specific depressing effect on cytokines in the cerebral cortex and in the hippocampus it appeared similar to the above, but of lower level. Anti-inflammatory activity of curcumin led to the recovery of memory parameters. Analysis of restriction sites of AßPP has shown that position of curcumin in Site II is energetically more favorable for binding. Our suggestion that curcumin is an effective anti-cytokine factor was confirmed by experimental results obtained in vivo and explain the mechanism describing its effect on NF-kB Curcumin doesn't block the excision $\mathrm{A} \beta$ but binding with its hydrophobic region.
\end{abstract}

Keywords: Alzheimer's Disease, Curcumin, Amyloid- $\beta$, Cytokine, Rat, Docking

\section{Introduction}

Recently, aggregation of amyloid- $\beta(A \beta)$ to form fibrils or depositions is considered to be one of the belivable factors of the pathology of Alzheimer's disease (AD), being the major pathogenetic event [1-4]. In particular, several studies have shown that $A \beta$ accumulates abundantly in certain brain areas namely, hippocampus and cerebral cortex which subserve information acquisition and processing, and memory [5-7]. This peptide is formed within the amyloyidogenic processing of the amyloid- $\beta$ protein precursor (A $\beta$ PP) [8-10].

Alternatively, processing within the non-amyloidogenic pathway involves full-length А $\beta$ PP cleaved by $\alpha$ - and $\gamma$ secretases in the trans-Golgi network apparatus and plasma membrane, precluding amyloid- $\beta$ formation (or amyloidogenesis). The inverse internalization of certain A $P$ P parts of the plasma membrane and their transport to late endosomes leads to $A \beta$ isoforms excision, which have 38-43 amino acid residues in length, caused by $\beta$ - and $\gamma$ secretases cleavage [11]. A variety of factors is believed to play a role of switch between non-amyloidogenic and amyloidogenic A $\mathrm{PP}$ processing pathways, such as A $\mathrm{PP}$ excess, degree of its phosphorylation, receptor SORL1 expression intensity, the presence of mutations in $А \beta P P$ and 
presenilins [12-16].

Endogenous $A \beta$ is a critical player in the synaptic plasticity and memory in normal central nervous system [1719]. It has been proposed that at low (picomolar) $A \beta$ concentrations could act as the trophic signal and modulator of synaptic activity, with implications in memory and learning [20-22]. Furthermore, $A \beta$ could work as antioxidant, due to its ability to capture redox metals, such as $\mathrm{Cu}, \mathrm{Fe}$ and $\mathrm{Zn}$, and, thus, prevent their participation in redox cycles with other ligands; hence $A \beta$ has the ability to function as a chelator and antioxidant molecule [23-25]. Amyloid- $\beta$ may be vital for the development of neurons, their plasticity and survival due to its integral membrane interactions, in maintaining the structural integrity of the blood brain barrier (BBB); it has antimicrobial properties and modulates intracellular $\mathrm{Ca}^{2+}$ transporting evoked by cholinergic receptors [26-30].

At high concentrations of $\mathrm{A} \beta$ (nanomolar to micromolar), neurotoxic aggregates are formed: oligomers or fibrils, resulting in amyloidosis and cell death [31-33]. The mechanism by which amyloid- $\beta$ can cause neurons damage and death is reactive oxygen species generating during its self-aggregation process. At the same time lipid peroxidation is activated on neuron membranes and functions of ionmotive ATPases (glucose and glutamate transporters) are impaired

http://en.wikipedia.org/wiki/Glutamate_transporters. As a result $A \beta$ promotes depolarization of the synaptic membrane, excessive calcium influx and mitochondrial impairment [3436]. These processes are accompanied by non-specific inflammatory reaction, which becomes chronic, and induce the synthesis of A $\beta P P$ and its processing by amyloyidogenic script [37-39].

Existing therapeutic approaches to the treatment of amyloidosis in Alzheimer's disease focused on reducing the production and aggregation of amyloid- $\beta$ [40-42] or symptomic therapy are ineffective [43-47].

Since has previously been shown that $\mathrm{AD}$ is accompanied by an inflammatory response, particularly higher peripheral concentrations of cytokines (IL-6, TNF $\alpha$, IL- $1 \beta$ and other) and higher CSF concentrations of TGF- $\beta$ [39], we focused on the correction of chronic inflammation that triggers $A \beta$ excess and aggregation and should have a positive impact. Proinflammatory cytokines, namely IL- $1 \beta$ and TNF $\alpha$, IL-6 is ambivalent and IL-10 (anti-inflammatory), in a line with $\mathrm{A} \beta$, are mediators of innate immunity [48, 28]. Their action is realized through receptor activation of intracellular signals leading to translocation of $\mathrm{NF}-\kappa \mathrm{B}$ in the nucleus and activation of protein synthesis de novo [49-50]. However, the existing anticytokine therapy is not proven, with exception of the anti-inflammatory IL-10 [51-52].

Curcumin (CUA) has been shown to regulate negatively transcription factors NF- $\mathrm{B}, \mathrm{AP}-1$; to suppress the expression of cyclooxygenase-2, lipoxygenase, NO synthase, matrix metalloproteinase-9, urokinase-type plasminogen activator, TNF, chemokines, cell surface adhesion molecules and cyclin D1; to inhibit the expression of growth factor receptors and activity of JNK, protein tyrosinekinases, and several other protein serine/threonine kinases [53-56]. This natural polyphenol is nowadays well described as an inhibitor of DNA methyltransferase so that it is considered as a DNA hypomethylating agent. It reestablishes the balance between histone acetyl transferase and histone deacetylase (HDAC 1, $3,4,5,8)$ activity to selectively activate or inactivate the expression of genes. Finally, curcumin modulates the activity of miRNAs (miR-15a, miR-16, miR-21, miR-22, miR-26, miR-101, miR-146, miR-200, miR-203, and let-7) and their multiple target genes [57].

It was found that CUA is able to be mounted in the fibrils amyloid- $\beta$ and encourage their disaggregation by forming a salt bridge with amino acid residues of the polypeptide chain, namely, Asp23 and Lys28, competing thus with metal ions $\mathrm{Zn}^{2+}$ or $\mathrm{Cu}^{2+}$ [58]. However, the probability interaction of CUA with sites of A $\beta$ PP cleavage by relevant secretases is of great interest [59].

The purpose of the research was to study the influence of anti-inflammatory effect of curcumin and modeling of its complexation with a fragment of A $\beta$ PP (Fragment_63Rat) that containing $A \beta$.

\section{Materials and Methods}

\subsection{Design of Research}

Investigation was carryed out on 30 white mature male Wistar rats six-month age weighting 200-250 g. All animals were maintained with a controlled 12-h light-dark cycle and standard rodent chow and tap water. The experimental protocols were performed in accordance with General ethical principles of animal experiments (Kiev, 2011), European Convention for the Protection of Vertebrate Animals used for experimental and other Scientific Purposes (Strasbourg, 1986) and the internationally recognized principles for the use and care of laboratory animals, asstated in the US guidelines [60].

The rats were divided into 5 groups at random $(n=6$ in each group). The Control group included of intact animals with conditioned active escape reflex, but without any effects. Main group 1 includes rats 1 month after intracerebral introduction A $\beta 42$ Human to hippocampus (AD animal model); Comparison group 1 - false-acts animals; Main group 2 - rats with AD experimental model, which obtained nasal therapy with an aqueous CUA solution during 1 month daily and Comparison group 2 - animal with AD animal model, which obtained nasal therapy with diluent (bidistilled water) during 1 month.

\subsection{Cognitive and Memory Tests}

Previously 20 days before, a conditional active escape reflex was formed in all rats based on the unconditional reflex. In a cage, which is equipped with a window wall, a conditional signal was performed to the animals (metronome sound with a frequency of 300 beats per minute). A rat had to cross through a window to the part of the cage for 15 
seconds. If the conditioned active escape reflex was conditional reflex escaper's action absent the unconditional signal was performed to the animal (electric current on a metal grid floor of the cage with a voltage of 30-40 for 10 seconds). The conditional signal was performed to each rat five times a day with pauses 1-3 seconds every day. The positive result was considered conditional reflex answers to metronome sound without mistakes. In animals as quantitative indicators of cognitive ability and memory have registered of the part of positive reactions (in percent) and the duration of latency periods of conditional reflex answers in seconds [61]. The duration of latency period was determined with stopwatch beginning from the metronome start until the rat moved in the other part of the cage.

These indicators of conditioned active escape reflex tested animals of all groups after animal model of $\mathrm{AD}$ formation and curcumin therapy, respectively.

\subsection{Alzheimer's Disease Animal Model and Curcumin Therapy}

Effects of A $\beta 42$ Human in homoaggregate form was studied after 1 month after a single administration at a dose of $15 \mathrm{nM} \mathrm{A} \beta 42$ Human $(65 \mu \mathrm{g})$ to hippocampus of rats. The volume of the solution was $10 \mu \mathrm{l}$ per animal. A $\beta 42$ was delivered to the hippocampus in stereotaxic installation using chromatographic syringe at a rate of $0.03 \mu \mathrm{l}$ per second for 5 $\min$.

A $\beta 42$ Human (Human Amyloid $\beta$ Protein Fragment 1-42, Sigma-Aldrich) dissolved in bidistilled water was aggregated for 24 hours at $37^{\circ} \mathrm{C}$. Large, coarse conglomerates A $\beta 42$ Human dispersed by ultrasound and sterilized immediately before introduction.

Stereotactic coordinates of the left hippocampus were determined according by the map of the brain by J. Bures [62], which corresponds to the distance from the point of intersection of the sagittal suture with bregma (zero point): distal - $2 \mathrm{~mm}$, lateral $-2 \mathrm{~mm}$ and in depth $-3.5 \mathrm{~mm}$. Stereotactic operation were carried out on rats under the general anesthesia by means of intraperitoneal injections of thiopental, $50 \mathrm{mg} / \mathrm{kg}$ body weight.

Since curcumin is poorly soluble in water, concentrated stock curcumin solution was originally prepared in $96 \%$ ethanol. CUA remained stable in ethanol at room temperature for several weeks, but degraded in water at neutral or mildly basic $\mathrm{pH}$ [63]. Therefore, CUA stock solution was freshly diluted daily to $0,7 \mathrm{~g} / \mathrm{l}$ in bidistiller water (the ratio alcohol: water in the working solution of curcumin was 1:100) immediately before every nasal administration to rats using a disposable pipette at a dose of $3,5 \mu \mathrm{g}$ per animal.

The animals were decapitated after treatment and their brain and blood were obtained quickly. Hemispheres were dissected and interesting regions (hippocampus and cerebral cortex) were removed, frozen and stored until ELISA analysis of cytokines. Blood was collected and centrifuged at $1000 \times \mathrm{g}$ for 20 minutes. Serum was collected, frozen and stored until cytokine tested. The hippocampal and cerebral cortex tissues were homogenized in Tris buffer (50 mM Tris-
$\mathrm{HCl}, 150 \mathrm{mM} \mathrm{NaCl}, \mathrm{pH} 7.5$ ), centrifuged at $14,000 \times \mathrm{g}$ for 5 minutes and collected supernatant.

\subsection{Cytokine Quantification Perfomed by Enzyme-Linked Immunosorbent Assays}

Samples of hippocampal and cerebral cortex supernatant and blood serum were processed to quantitively measure the amount of cytokine ELISA method in accordance with the manufacturer's instructions Rat ELISA Kits Invitrogen BCM DIAGNOSTICS, USA for interleukin-1 $\beta$ (IL-1 $\beta$ ), interleukin6 (IL-6), interleukin-10 (IL-10) and tumor necrosis factor- $\alpha$ $(\mathrm{TNF} \alpha)$. OD was read by microplate analyzer GBG Stat FAX 2100 (USA) at $450 \mathrm{~nm}$ with the wavelength correction at 630 $\mathrm{nm}$ [64]. ELISA assay data ( $\mu \mathrm{g} / \mathrm{l}$ cytokine) were normalized to $\mathrm{g}$ total protein or expressed at $\mathrm{ng} / \mathrm{l}$ of blood serum. On figures, were the obtained indexes are presented as a percent from Control indexes. Total protein content was determined by Lowry [65].

\subsection{Molecular Dynamics (MD) Simulations and Protein Ligand Docking}

To simulate the interactions of curcumin with A $\beta P P-$ fragment Fragment_63Rat - A4_RAT (P08592: Ile661Leu720) of 63 amino acid residues, containing amyloid- $\beta$ and the three restriction site for $\beta-, \alpha$ - and $\gamma$-secretase, was selected. Because of the lack of experimentally obtained protein structures, homology modeling was impossible. Therefore, we performed a preliminary parameterization and analysis of hypothetical spatial organization using protein secondary structure prediction servers: ProtParam (http://web.expasy.org/protparam/) and SOPMA (http://npsapbil.ibcp.fr/) for modeling using several templates and de novo methods [66-67].

3D-models of Fragment_63Rat were built using ITASSER (http://zhanglab.ccmb.med.umich.edu/I-TASSER/) and SWISS-MODEL (http://swissmodel.expasy.org) profile modeling servers, QUARK de novo modeling tool (http://zhanglab.ccmb.med.umich.edu/QUARK/), and original algorithm of de novo mathematical modeling tool Molecular Constructor [68]. Optimization of built models geometry and verification of folding were performed using a full-atomic force field CHARMM [69] and software package GROMACS 4.5 [70]. Checking of models stability was based on root-mean-square deviation between C-atoms (RMSD) and total conformational energy - CE (the energies of van der Waals and Coulomb interactions) [71].

To evaluate curcumin as potential inhibitor of enzymatic restriction, we used flexible molecular docking in CCDC GOLD Suite 5.1. Parameterization of molecular target (Fragment_63Rat), ligand (curcumin) and conditions of docking were performed according to CCDC recommendations, with the maximum docking site: maximum radius from selected atom. Evaluation of the docking, potential affinity of ligand and binding site was performed basing on evaluation functions of CCDC GOLD (http://www.ccdc.cam.ac.uk): GoldScore and ASP [72]. 
Visualization and analysis of molecular modeling and docking results were performed in PyMOL [73] and BIOVIA DS Visualizer (http://accelrys.com/).

\subsection{Statistical Analysis}

The results were treated statistically; the average values and standard deviations were calculated. Statistical analysis of differences was performed using Student's t-test for the corresponding Main and Comparison groups, and among Control indexes. The value of $p<0.05$ was considered significant.

\section{Results}

\subsection{Cytokines Changes in Chronic Neuroinflammation Induced Homoaggregates of $\beta$-Amyloid Peptide 42 Human (AD Animal Model) in Rats}

Expressive changes in the content of IL- $1 \beta$, TNF $\alpha$, IL-6 and IL-10 in blood serum of the animals with AD animal model (Main group 1) was not revealed comparing with the Control group. As shown in Table 1, only serum concentrations of TNF $\alpha$ increased by $20 \%$ and IL-10 declined by $54 \%$, respectively. Similar trends were noted in the Comparison group 1 (false-acts animals). Thus, cytokine levels in blood serum doesn't reflect the specific action of A $\beta 42$ Human in the brain, but the result intracerebral intervention.

Table 1. Action of AB42_Human of homoaggregate and curcumin on IL-1 $\beta, T N F \alpha$, IL-6 and IL-10 in blood serum of examine rats.

\begin{tabular}{|c|c|c|c|c|c|}
\hline Cytokine & Control group (ng/l) & Main group 1 (ng/l) & Comparison group 1 (ng/l) & Main group 2 (ng/l) & Comparison group 2 (ng/l) \\
\hline IL-1 $\beta$ & $17.2 \pm 1.2$ & $16.8 \pm 1.1$ & $15.7 \pm 0.6$ & $20.9 \pm 2.3 * \# \&$ & $16.2 \pm 1.2$ \\
\hline $\mathrm{TNF} \alpha$ & $7.9 \pm 0.8$ & $9.5 \pm 0.6 *$ & $10.7 \pm 1.0 *$ & $10.3 \pm 1.4 * \#$ & $13.0 \pm 1.2 * \&$ \\
\hline IL-6 & $4.8 \pm 1.0$ & $3.7 \pm 0.6$ & $5.3 \pm 1.1$ & $1.8 \pm 0.5 * \&$ & $1.8 \pm 0.3 * \&$ \\
\hline IL-10 & $3.9 \pm 0.4$ & $1.8 \pm 0.2 *$ & $1.3 \pm 0.2 * \#$ & $4.0 \pm 0.5 \# \&$ & $1.6 \pm 0.2 *$ \\
\hline
\end{tabular}

The results given as the mean value $\pm \mathrm{S}$. D.

* $-\mathrm{p} \leq 0.05$ in comparison with Control; ${ }^{\#}-\mathrm{p} \leq 0.05$ among suitable Comparison group; ${ }^{\&}-\mathrm{p} \leq 0.05$ in comparison with Main group 1 (AD animal model)
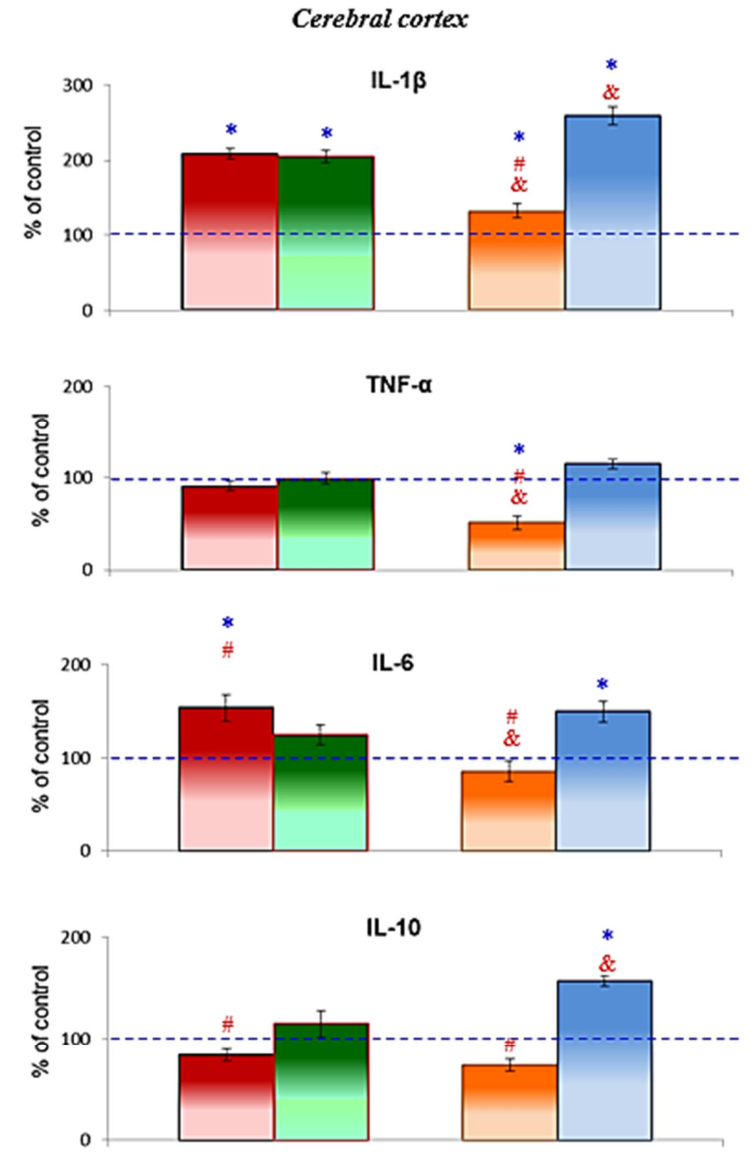

-Main group 1 ¿Comparison group 1 ¿Main group 2 -Comparison group 2

-..- Control values, taken as $100 \%$

Figure 1. Effect of AB42_Human and CUA therapy on levels of cytokines (IL-1 $\beta, T N F \alpha, I L-6, I L-10)$ in the cerebral cortex of brain rats. The results are expressed in \% of Control, and given as the mean value $\pm S$. D. * $-p \leq 0.05$ compared to Control; \# - $p \leq 0.05$ among suitable Comparison group; \& $-p \leq 0.05$ compared to Main group 1 (AD animal model). 
The study of cytokines in the cerebral cortex of the rats with $\mathrm{AD}$ animal model (Main group 1) showed a low-grade inflammatory response, namely increase in level of IL-6 by $29 \%$ and reduce of IL-10 by $31 \%$, comparing to the concentrations in false-acts animals (Fig. 1). Significant increase in level of IL- $1 \beta$ by $109 \%$ of the rats with AD animal model compared with those of Control group corresponds to level of this cytokine in Comparison group 1 $(105 \%)$. This could come from injection itself. The content of $\mathrm{TNF} \alpha$ in the cerebral cortex and hippocampus of rats of Main group 1 and Comparison group 1 did not differ from Control index and among themselves.

Hippocampal levels of IL-1 $\beta$ and IL-10 in rats with AD animal model increased significantly, compared with those in Control (by 221\% and 111\%) and Comparison 1 (by $110 \%$ and $78 \%$ ) groups. In this brain part, concentration of IL-6 rats of the Main group 1 did not differ from values in intact animals, but was reduced by $44 \%$ against IL- 6 concentration in false-acts rats (Fig. 2). These data suggest that homoaggregates of $\mathrm{A} \beta 42$ Human in the hippocampus of AD animal model rats provoked chronic neuroinflammation specifically and primarily at this region of the brain. However, in the cerebral cortex of these rats activation of inflammation reaction was also featured, albeit to a lesser extent. This result confirms our previous research, in which it was shown that homoaggregates of A 340 Human introduction into the cerebral cortex of rats causes more cytokine response in that part of the brain of rats in comparison with the situation in hippocampus [74].

\section{Hippocampus}
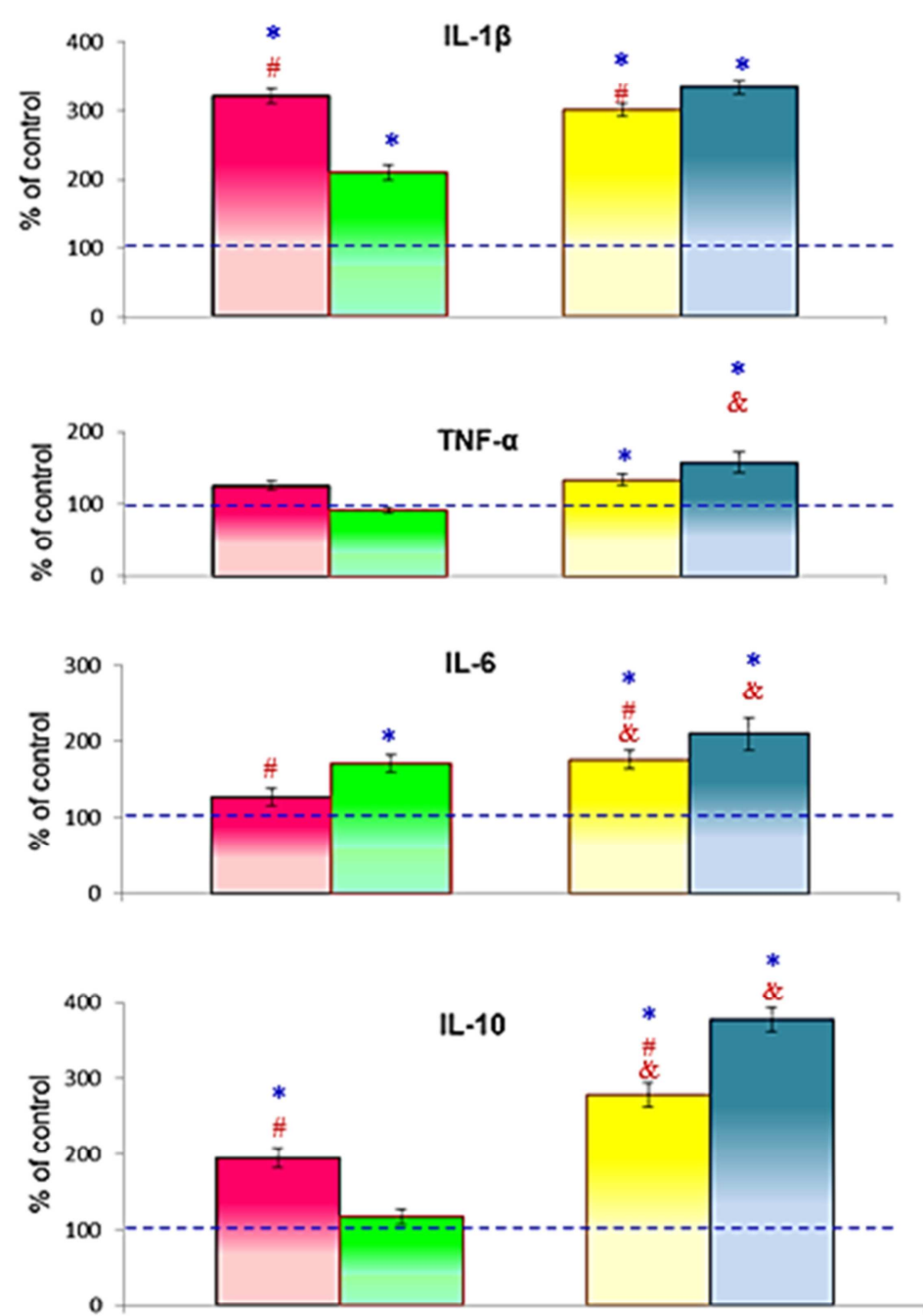

-Main group $1 \quad$ aComparison group $1 \quad$ aMain group $2 \quad$-Comparison group 2

--- Control values, taken as $100 \%$

Figure 2. Effect of AB42_Human and CUA therapy on levels of cytokines (IL-1 $, T N F \alpha, I L-6, I L-10)$ in the hippocampus of brain rats. The results are expressed in \% of Control, and given as the mean value $\pm S . D .{ }^{*}-p \leq 0.05$ compared to Control; \# - $p \leq 0.05$ among suitable Comparison group; \& - $p \leq 0.05$ compared to Main group 1 (AD animal model). 
Intrahippocampal introduction of A $\beta 42$ Human homoaggregate caused inhibition of conditional active escape reflex in rats of Main group 1. The study of cognitive capabilities and memory revealed reduction of the proportion of positive reactions and increase of latent period in these animals among rats of Control group (Fig. 3). However, the part of positive reactions with $\mathrm{AD}$ animal model rats did not differ from the index of false-acts animals, describing the effect of intracerebral interventions.
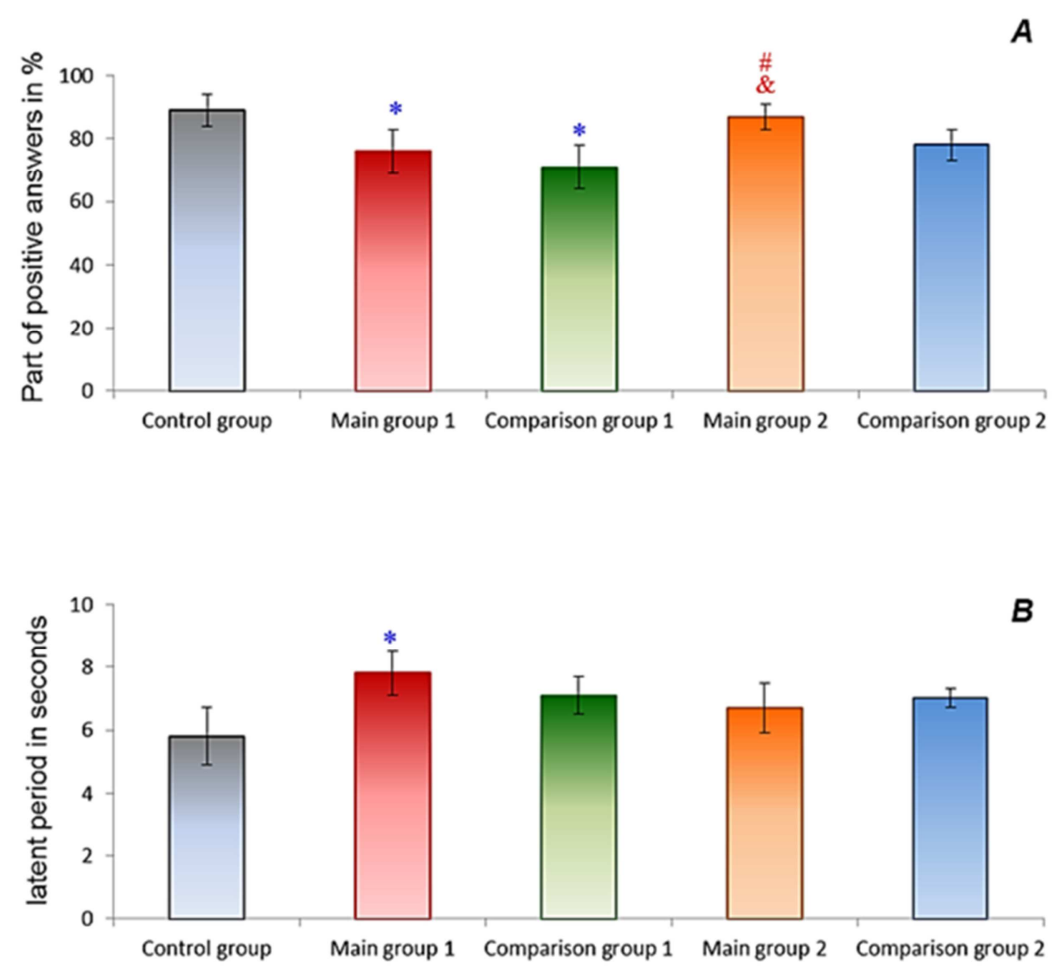

Figure 3. Changes of part of positive reactions $(A)$ and latent periods (B) by the action AB42 Human and CUA therapy in rats. The results given as the mean value $\pm S . D . *$ - $p \leq 0.05$ compared to Control; \# - $p \leq 0.05$ among suitable Comparison group; $\&$ - $p \leq 0.05$ compared to Main group 1 (AD animal model).

\subsection{Effect of Curcumin on the Concentration of IL-1B, TNFa, IL-6, IL-10 in Rats with AD Animal Model}

Daily CUA therapy of rats with AD-model for 1 month led to increase of levels of proinflammatory cytokines: IL-1 $\beta$ (by $22 \%$ ) and TNF $\alpha$ (by 30\%) and reducing of ambivalent IL-6 (by $38 \%$ ) in blood serum compared of Control (Table 1).

In the Comparison group 2 (nasal administration of bidistillate instead of CUA solution to rats with $\mathrm{AD}$ animal model) content of IL- $1 \beta$ remained unchanged, but dynamic concentrations of TNF $\alpha$ and IL-6 coincided with the Main group 2. However, CUA renewed quite specifically concentration of anti-inflammatory IL-10 in serum of rats in contrast to the effect of bidistilled water. In general, cytokine response in blood circulation of experimental rats is activated by curcumin treatment.

Curcumin performance in the cerebral cortex revealed specific depressing effect on cytokines (Fig. 1). Namely, the normalized level of IL- $1 \beta$ and IL-6; TNF $\alpha$ reduced by $49 \%$ compared to Controls; IL-10 level did not change, but at the same time it did not differ from control indexes. The further aggravation of neuroinflammation induced by intrahippocampal injection of A $\beta 42$ Human was observed in Comparison group 2, the concentrations of IL-1 $\beta$ and IL-10 in this area of the brain increased by $50 \%$ and $73 \%$, respectively, after 1 month of bidistillate treatment, what corresponds to 2-month term impact of A 442 Human compared with Main group 1.

In the hippocampus of animals, CUA effect on cytokine appeared similar to the above, but below the level (Fig. 2). The cytokines concentration did not normalize, while level of IL-6 and IL-10 increased by $49 \%$ and $83 \%$ respectivly, compared with the indexes month ago (Main group 1). But when comparing hippocampus cytokines of Main groups 2 rats of Comparison groups 2 becomes clear specific CUA induced inhibition levels of IL-1 $\beta$ (by 33\%), TNF $\alpha$ (by 24\%), IL-6 (by 34\%) and IL-10 (by 99\%). The observed antiinflammatory activity of CUA led to the recovery of memory parameters, in particular concerning positive reactions of animals (Fig. 3).

\subsection{Fragment_63Rat Docking with Curcumin}

During experiments on prediction of the spatial structure of Fragment_63Rat (Ile661-Leu723 of APP) we have selected 8 models: one built by a server profile simulations SWISS-MODEL (63_SM), 1 built de novo using the tool conformational search QUARK (63 Q), 5 models were built using I-TASSER server (63_IT1-5) and 1 model was reconstructed using original de novo mathematical modeling tool - Molecular Constructor (63_MC). 
Analysis of the physicochemical properties of built models using ProtParam tool provided us with information necessary for further parameterization of input files for molecular dynamics in Gromacs. Short-term molecular dynamics was carried out using explicit solvent in the box. Its size was oversized (10 $\AA$ ) because of high mobility and the lack of information on conformational mobility of Fragment_63Rat. Geometry optimization via free energy minimization was performed using computational modules «grompp», «mdrun», ffgmx force field, and Steepest Descent Algorithm (maximum number of steps $=1000$ and gradient $=0.1$ ) Molecular dynamics simulations $\left(5 \mathrm{~ns}\right.$ at $\left.\mathrm{T}=310^{\circ} \mathrm{K}\right)$ were performed using full atomic force field.

There were no messages about incorrect or invalid values of conformational parameters during the calculation of Fragment_63Rat molecular dynamics. What in part demonstrates the high quality and stability of constructed models [75-76]. Results of molecular dynamics were analyzed taking into account two criteria: standard deviation between $\mathrm{C}$ - $\alpha$-atoms (conformational fluctuations, RMSD) and protein conformational energy (total energy of van der Waals and Coulomb interactions, CE), using previously proven protocol (Fig. 4) [75, 77].
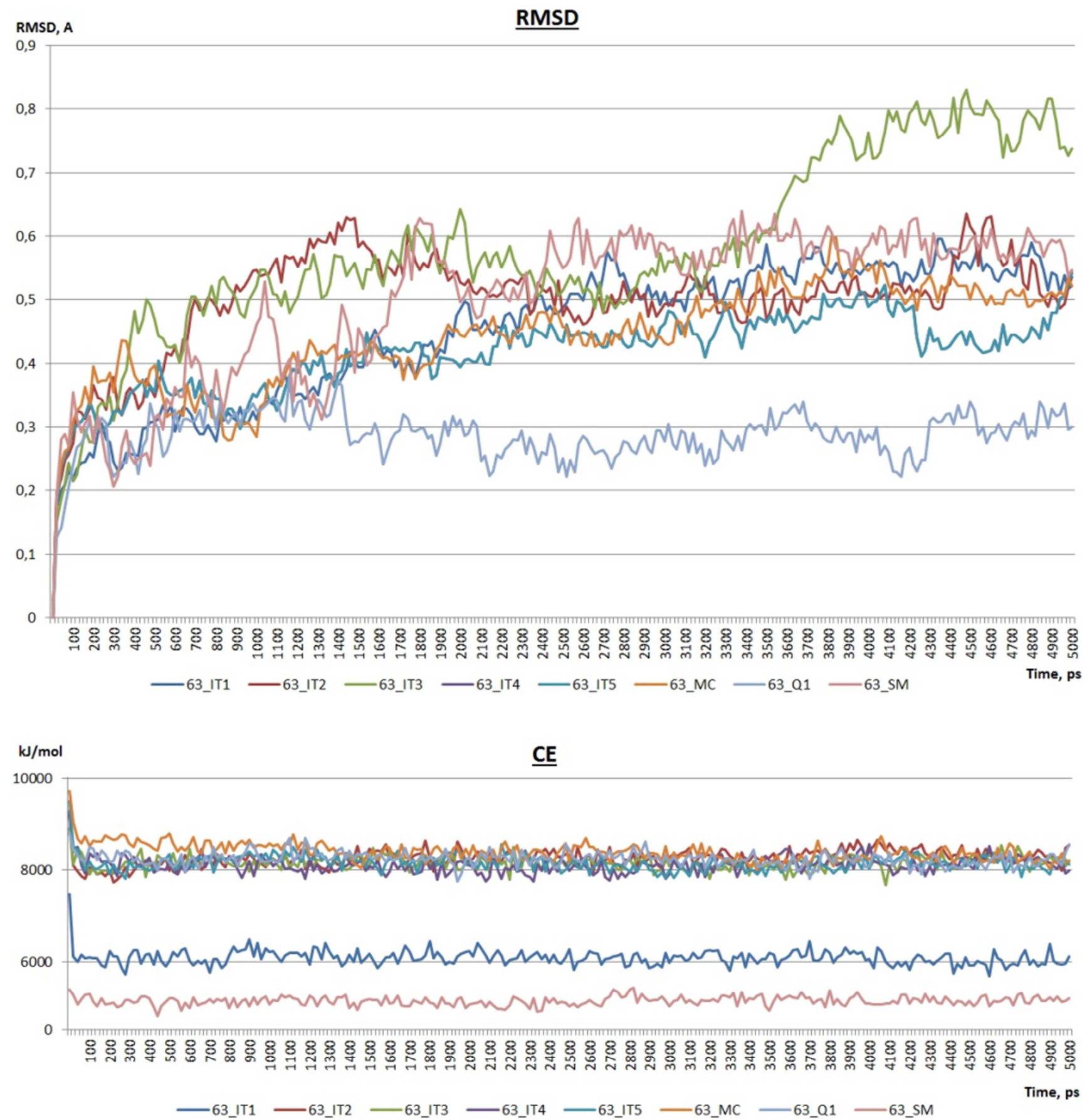

Figure 4. Standard deviation between Co-atoms (RMSD) and conformational energy (CE) of built models of Fragment_63Rat according to results of molecular dynamics simulations. 
High conformational mobility of some models during MD simulations is potentially associated with a large amount of unstructured elements. Despite high fluctuations of 63_IT3 and highest stability of 63 Q, their energy fluctuations are well correlated with all models except for 63_SM and 63 IT5. Subsequent analysis was performed for average normal energy models $(t=4-5 \mathrm{~ns})$ using internal tools of Gromacs. Based on results of molecular dynamics, for docking with a molecule of curcumin, two models of target

Site I Site II

$\begin{array}{ccc}\text { Site I } & \text { Site II } & \text { Site III } \\ \beta \text {-secretase } & \alpha \text {-secretase } & \gamma \text {-secretase } \\ \text { I }_{651}-\mathrm{L}_{723}: \text { IKTEEISEVK MDAEFGHDSG } & \text { FEVRHQKLVF FAEDVGSNKG AIIGLMVGGV VIATVIVITL VML } \\ 11-12 & 27-28 & 51-52\end{array}$

protein were selected (Fig. 5): 63_Q - a model with best performance and energy of conformational fluctuations, and 63_IT3 - a model, characterized by the presence of unique elements of secondary structure, inherent in this group of proteins [78]. Preliminary we have selected three sites of enzymatic restriction of Fragment 63Rat: I - Met11-Asp12 (for $\beta$-secretase); II - Lys27-Leu28 (for $\alpha$-secretase); III Val51-Ile52 (for $\gamma$-secretase).
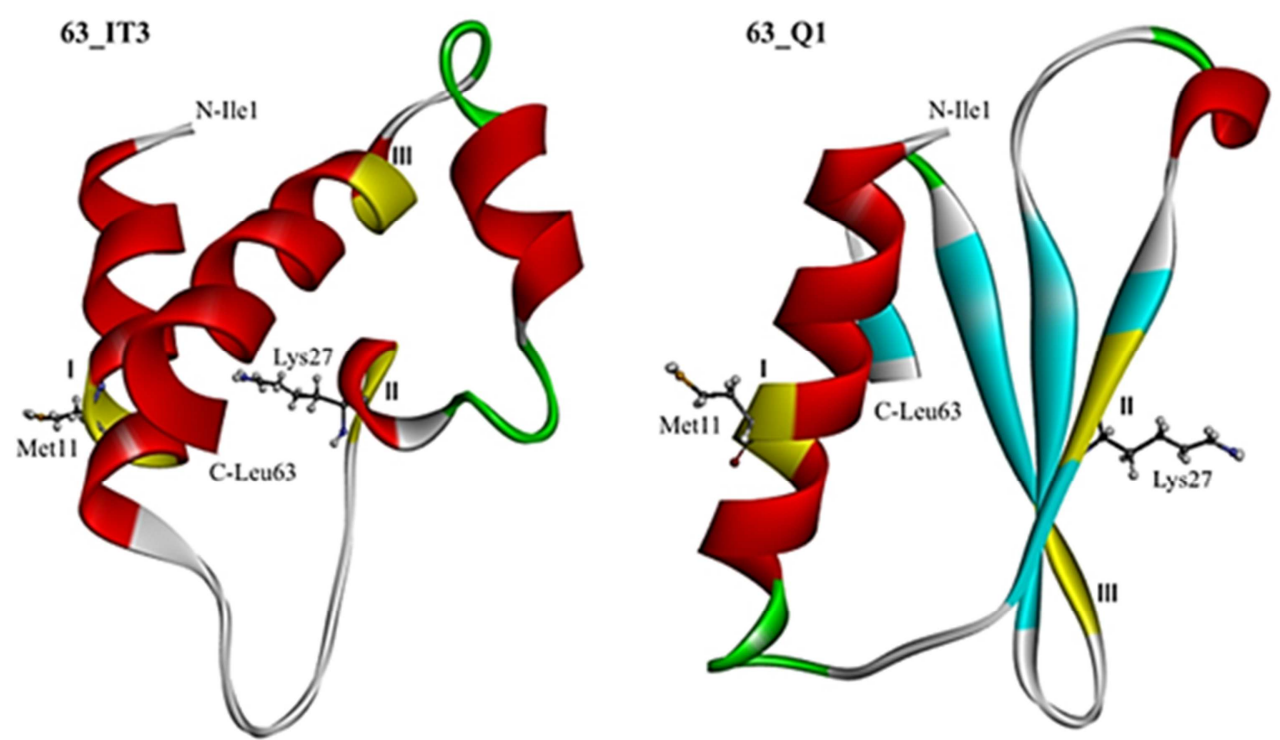

Figure 5. A ribbon diagrams of the spatial structure models of rat fragment 63 reconstructed by profile (63 IT, I-TASSER server) and de novo (63 Q1, service QUARK server) methods.

Note: Yellow color shows possible sites of enzymatic restriction - (I) Met11-Asp12 ( $\beta$-secretase); II - Lys27-Leu28 ( $\alpha$-secretase); III - Val51-Ile52 ( $\gamma$ secretase).

It was found that according to constructed model, site III located on unstructured and moveable part of peptide (Fragment_63Rat) preventing binding of CUA at this area. At the same time, Site I and Site II definitely have more favorable structure for binding such structures and were selected for subsequent molecular docking. As ligands, we used two conformations of CUA: 1) extracted from PDBstructure of TTR (PDB: 4PMF) and 2) chosen according results of conformational search. After checking accuracy of atoms and bonds, ligands were saved in full atomic format* mol2, and prepared for docking using Hermes program by CCDC Software Ltd. Analysis of 63 IT3 and 63_Q sites of CUA binding was performed using a flexible molecular docking using CCDC GOLD genetic algorithm. Default settings of CCDC GOLD were used, except choice of site central atom and radius of docking region. In this case, choice of sites was caused by location of two amino acid residues - experimentally predicted sites of enzymatic restriction. In the case of the first site (Site I), centering was made on Met11, and CA of model 63_IT3 and CB of model 63_Q1 were used as central atoms of target. In the case of the second site (Site II), centering was carried out on Lys27, and CA of model 63 IT3 and CB of model 63 Q1 were used as central atoms of target. For docking, a complete mobility of the ligands was set. Amino acid residues of target were fixed, and the radius of docking site was increased up to $15 \AA$, covering the major part of model surface. In the first case, genetic algorithm was run in 100 time repetition, and in the second case, it was run in 10 times based on 10-best frames selected in the first stage. Internal evaluation functions of CCDC GOLD were used as selection criteria. Thus, the value of key function - GoldScore indicate affinity of ligand to binding site (higher value - better), and ASP value indicates comfort of conformational state of the ligand itself (smaller 
value - better). Coincidence of favorable values of GoldScore and ASP was a marker for selection of leading models of curcumin-Fragment_63Rat interaction. According to aforementioned algorithm, we found coincidence of two conformational states of curcumin in complexes with 63_Q and 63_IT3. These conformations were selected based on statistical indicators of CCDC GOLD, and advantageous conformational states of selected ligands. In the leading models of curcumin-Fragment_63Rat complexes (Fig. 6) methyl group of CUA are placed within a hydrophobic pocket of the target, and oxygen groups form stable hydrogen bonds. We consider that conformation of the model 63_Q is

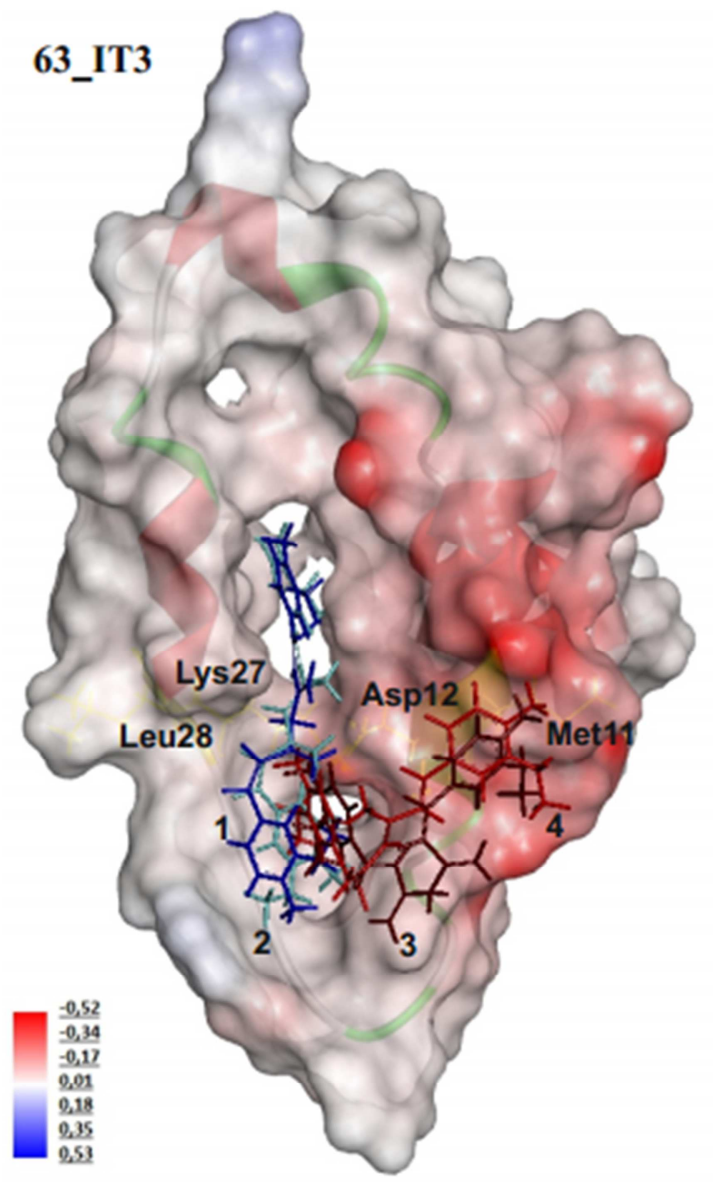

more probable for curcumin binding, due to presence of conformationally stabile elements of secondary structure, results of statistic and molecular dynamics. SOPMA method of secondary structure prediction, with a probability of $73 \%$ makes it possible to establish the main elements of primary structure of polypeptide chain: $\alpha$-helix, $\beta$-fold, $\beta$-turns and irregular structure areas. Comparative analysis of Site I and Site II based on the ChemScore evaluation algorithm of CCDC GOLD has shown that position of curcumin in Site II is not only conformationally, but also energetically more favorable for ligand binding.

\section{3_Q1}

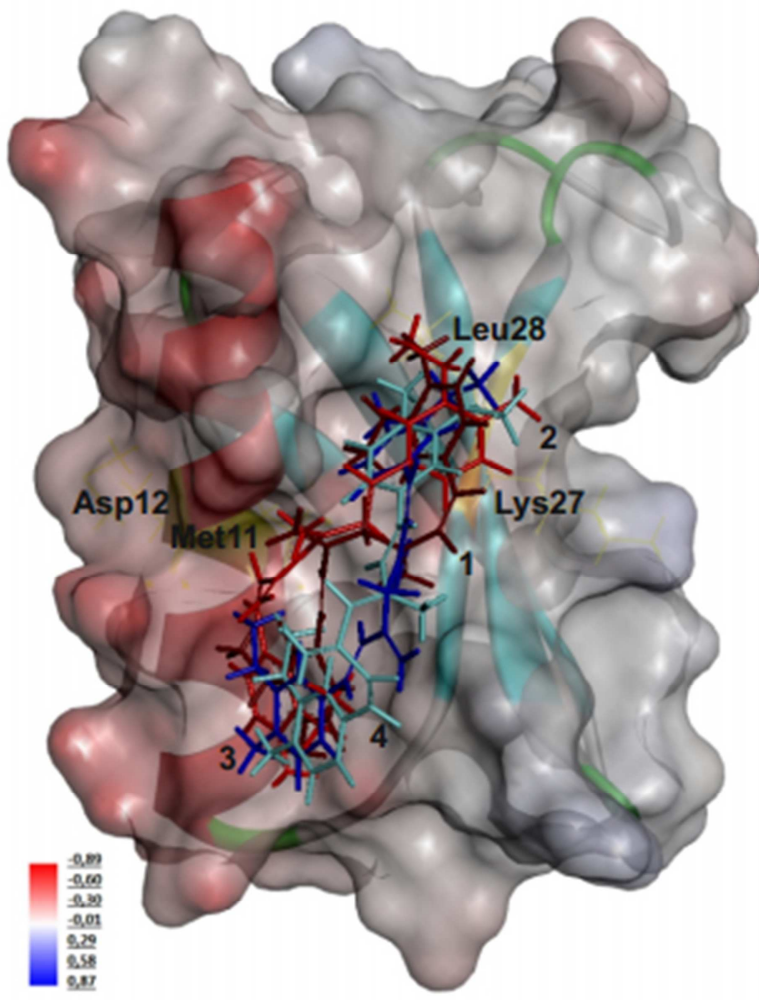

Figure 6. Structure models of curcumin-Fragment_63Rat complex.

Site I (Met11-Asp12): 1) using conformation of curcumin extracted from PDB-structure of TTR (PDB: 4PMF), 2) using conformer of curcumin, selected based on conformational search;

Site II (Lys27- Leu28): 3) using conformation of curcumin extracted from PDB-structure of TTR (PDB: 4PMF), 4) using conformer of curcumin, selected based on conformational search.

Our results indicate, that suppose of the possible interaction of curcumin with aforementioned sites (Site I for $\beta$-secretase and Site II for $\alpha$-secretase) of enzymatic restriction has a right to exist.

\section{Discussion}

Ours results demonstrated activation of cytokines system in rat's brain with $\mathrm{AD}$ animal model (Fig. 1-2). These data confirms numerous researches about neuroinflammation induced by $\mathrm{A} \beta$ deposits, fibriles or oligomers [79-84]. $\mathrm{A} \beta$ deposition is responsible for microglia activation [79]. A $\beta$ enhances the inflammatory response to stimulation of NF- $\kappa B$, nuclear factor that is involved in the regulation of ERK (extracellular signal-regulated kinase) and MAPK (mitogenactivated protein kinase) pathways that lead to the production of cytokines and chemokines [80]. Toll-like receptors (TLR), along with IL-1R and TNFR, are important for regulation of microglial responses to $A \beta$. Modification of the inflammatory state of microglia/macrophages may play an axial role in $\mathrm{AD}$ - 
related pathology [81]. According to our data, chronic neuroinflammation induced by the administration of A $\beta 42$ Human to hippocampus manifested changes of TNF $\alpha$ and IL-10 serum levels (Table 1) and decline in cognitive and memory indexes in rats (Fig. 3). Therefore, hyperproduction of cytokines may play a role of realizing mechanism in the early stages of amyloidosis and Alzheimer's dementia.

Our suggestion that curcumin is an effective antiinflammatory factor was confirmed by experimental results obtained in vivo and explain the mechanism described its effect on NF- $\kappa \mathrm{B}$. It is known, that CUA can inhibit activation of the proinflammatory transcription factor $\mathrm{NF}-\kappa \mathrm{B}$, inhibiting phosphorylation and degradation of I $\mathrm{B} \alpha$, an inhibitor of NF$\kappa \mathrm{B}$. CUA is also a potent inhibitor of COP9 signalosome and associated kinases, casein kinase 2 and protein kinase $\mathrm{D}$, all linked to the ubiquitin-proteasomal system (UPS) [85-86]. Effect of curcumin is inhibition of IB kinase (IKK) activation, required for NF- $\kappa B$ activation [87-89]. That is what we explain the detected anticytokine effect curcumin in experimental animals (Fig. 1-2).

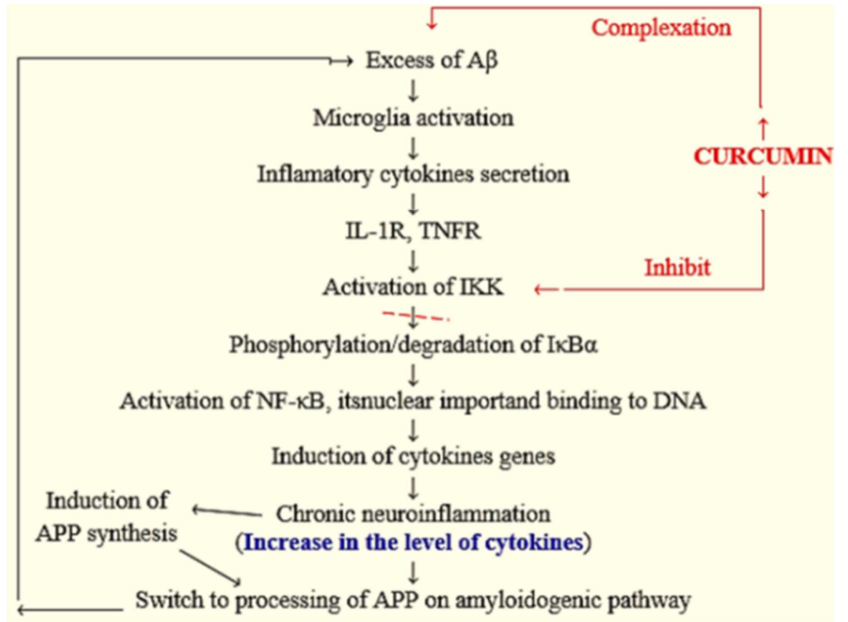

Figure 7. Hypotetical scheme of anticytokine activity of curcumin in ABindused animals and its binding to a fragment of $A \beta P P$.

Hypotetical scheme of A $\beta 42$ Human and curcumin influences through intersection point of cytokines signaling to the NF- $\kappa$ B pathway is shown in Fig. 7.

It has been shown that CUA inhibits the formation of $A \beta$ fibrils and has potential anti-amyloidogenic effect [90-93]. Similarly, nanoparticles functionalized with CUA derivatives [94] exhibit high affinity toward A $\beta 42$ monomers and the corresponding fibrils $[95,96]$. Recent studies of the complex A $\beta 42$ curcumin analysis of MD trajectories showed that the C-terminal $\beta$-strands at the site Ala21-Val40 are much rarer spirals and curcumin helps to stabilize the latter. In addition, calculations A $442-C U A$ complex showed its direct interaction with the hydrophobic cor $\mathrm{A} \beta 42$, which may explain why curcumin acts as an inhibitor of aggregation of A $\beta 42$ [97, 98]. They are hydrophobic residues Phe 10, Phe 19, Phe 20 and Leu34, which do not belong to the sites of the proteolytic clevage of $\mathrm{A} \beta \mathrm{PP}$ and are in their neighborhood, interacting with the hydrophobic region of the phenolic rings of curcumin. These data are consistent with those obtained in our work to sites I and II: in particular, all three phenylalanine surround processing site II of A $\mathrm{PP}$, while Phe10 and Leu34 are closer to sites I and III, respectively, (Figure 6). Therefore, anti-amyloidogenic effect of curcumin is not blocking the excision sites $A \beta 40$ or $A \beta 42$ but a binding of the hydrophobic region in beta-amyloid peptide and aggregation preventing. Thus, some levels of curcumin effect have been shown in experiments in vivo and in silico (Fig. 7), its anti-amyloidogenic influence is realized.

\section{Conclusions}

The role of neuroinflammation as a mechanism of cognitive impairments development has been shown by the experimental model of Alzheimer's disease in rats. An antiinflammatory effect of nasal treatment with an aqueous solution of curcumin has been determined. A scheme of curcumin action has been proposed taking into account the data of molecular docking with the АвPP fragment, containing area of Ав.

\section{Acknowledgements}

We would like to thank Prof. Olga Berchenko and Dr. Victor Barstein for their helpful discussions and comments on the manuscript.

\section{References}

[1] Sadigh-Eteghad S, Sabermarouf B, Majdi A, Talebi M, Farhoudi M, Mahmoudi J Amyloid-Beta: A Crucial Factor in Alzheimer's Disease. Med Princ Pract. 2015; 42: 1-10.

[2] Esparza TJ, Zhao H, Cirrito JR, Cairns NJ, Bateman RJ, Holtzman DM, Brody DL Amyloid-beta oligomerization in Alzheimer dementia versus high-pathology controls. Ann Neurol. 2013; 73: 104-119.

[3] Palop JJ, Mucke L Amyloid- $\beta$-induced neuronal dysfunction in Alzheimer's disease: from synapses toward neural networks. Nat Neurosci. 2010; 13: 812-818.

[4] Hardy J, Selkoe DJ The amyloid hypothesis of Alzheimer's disease: progress and problems on the road to therapeutics. Science. 2002; 297: 353-356.

[5] Grienberger C, Rochefort NL, Adelsberger H, Henning HA, Hill DN, Reichwald J, Staufenbiel M, Konnerth A Staged decline of neuronal function in vivo in an animal model of Alzheimer's disease. Nat Commun. 2012; 774: 1-10.

[6] Nakajima C, Kulik A, Frotscher M, Herz J, Schäfer M, Bock HH, May P LDL receptor-related protein 1 (LRP1) modulates $\mathrm{N}$-methyl-D-aspartate (NMDA) receptor-dependent intracellular signaling and NMDA-induced regulation of postsynaptic protein complexes. J Biol Chem. 2013; 30: 21909-21923.

[7] Selkoe DJ Soluble oligomers of the amyloid $\beta$-protein impair synaptic plasticity and behavior. Behav Brain Res. 2008; 192: 106-113. 
[8] O'Brien RJ, Wong PC Amyloid precursor protein processing and Alzheimer's disease. Annu Rev Neurosci. 2011; 34: 185204.

[9] Maltsev AV, Dovidchenko NV, Uteshev VK, Sokolik VV, Shtang OM, Yakushin MA, Sokolova NM, Surin AK, Galzitskaya OV Intensive pro-tein synthesis in neurons and phosphorylation of beta-amyloid precursor pro-tein and tauprotein are triggering factors of neuronal amyloidosis and Alzheimer's disease. Biomed Chem. 2013; 7: 278-293.

[10] Kim J-H, Anwyl R, Suh Y-H, Djamgoz MBA, Rowan MJ Use-dependent effects of amyloidogenic fragments of $\beta$ amyloid precursor protein on synaptic plasticity in rat hippocampus in vivo. J Neurosci. 2001; 21: 1327-1333.

[11] Hartmann T, Bieger SC Distinct sites of intracellular production for Alzheimer's disease A beta40/42 amyloid peptides. Nat Med. 1997; 3: 1016-1020.

[12] Colombo A, Bastone A, Ploia C, Sclip A, Salmona M, Forloni G, Borsello T JNK regulates APP cleavage and degradation in a model of Alzheimer's disease. Neurobiol Dis. 2009; 33: 518525 .

[13] Andersen OM, Reiche J, Schmidt V Neuronal sorting proteinrelated receptor sorLA/LR11 regulates processing of the amyloid precursor protein. Proc Natl Acad Sci USA. 2005; 102: $13461-13466$.

[14] Ridge PG, Ebbert MT, Kauwe JS Genetics of Alzheimer's disease. Biomed Res Int. 2013; 25: 49-54.

[15] Hsiao K, Chapman P, Nilsen S, Eckman C, Harigaya Y, Younkin S, Yang F, Cole G Correlative memory deficits, $A \beta$ elevation, and amyloid plaques in transgenic mice. Science. 1996; 274: 99-102.

[16] Fantini J, Garmy N, Mahfoud R Lipid rafts: structure, function and role in HIV, Alzheimer's and prion diseases. Expert Rev Mol Med. 2002; 4: 1-22.

[17] Puzzo D, Privitera L, Fa' $M$ Endogenous amyloid- $\beta$ is necessary for hippocampal synaptic plasticity and memory. Ann Neurol. 2011; 69: 819-830.

[18] Kimura R, MacTavish D, Yang J, Westaway D, Jhamandas JH Beta amyloid-induced depression of hippocampal long-term potentiation is mediat-ed through the amylin receptor. J Neurosci. 2012; 32: 17401-17406.

[19] Morley JE, Farr SA A physiological role for amyloid- $\beta$ protein: en-hancement of learning and memory. J Alzheimer's disease. 2010; 19: 441-449.

[20] Cárdenas-Aguayo MC, Silva-Lucero MC Physiological role of amyloid beta in neural cells: the cellular trophic activity. INTECH. 2014: 1-26.

[21] Cirrito JR, May PC, O’Dell MA In vivo assessment of brain intersti-tial fluid with microdialysis reveals plaque-associated changes in amyloid-beta metabolism and half-life. J Neurosci. 2003; 23: 8844-8853.

[22] Puzzo D, Privitera L Picomolar amyloid-beta positively modulates synaptic plasticity and memory in hippocampus. J Neurosci. 2008; 28: 14537-14545.

[23] Atwood CS, Obrenovich ME, Liu T, Chan H Amyloid-beta: a chame-leon walking in two worlds: a review of the trophic and toxic properties of amyloid-beta. Brain Res Brain Res Rev. 2003; 43: 1-16.
[24] Cetin F, Yazihan N, Dincer S, Akbulut G The effect of intrahippocampal beta-amyloid1-42 peptide injection on oxidant and antioxidant status in rat brain. Ann NY Acad Sci. 2007; 1100: 510-517.

[25] Curtain CC, Ali F, Volitakis I Alzheimer's disease amyloidbeta binds copper and zinc to generate an allosterically ordered membrane-penetrating structure containing superoxide dismutase-like subunits. J Biol Chem. 2001; 276: 20466-20473.

[26] Chen Y, Dong C Abeta40 promotes neuronal cell fate in neural pro-genitor cells. Cell Death Differ. 2009; 16: 386-394.

[27] Atwood CS, Bishop GM, Perry G, Smith MA Amyloid-beta: a vas-cular sealant that protects against hemorrhage? J Neurosci Res. 2002; 70: 356 .

[28] Soscia SJ, Kirby JE, Washicosky KJ, Tucker SM, Ingelsson M, Hy-man B, Burton MA, Goldstein LE, Duong S, Tanzi RE, Moir RD The Alz-heimer's disease-associated amyloid $\beta$ protein is an antimicrobial peptide. PLoS ONE. 2010; 5 (3): e9505.

[29] Gu Z, Zhong P, Yan Z Activation of muscarinic receptors inhibits be-ta-amyloid peptide-induced signaling in cortical slices. J Biol Chem. 2003; 278: 17546-17556.

[30] Jellinger KA Challenges in neuronal apoptosis. Curr Alzheimer Res. 2006; 3: 377-391.

[31] Goure WF, Krafft GA, Jerecic J, Hefti F Targeting the proper amy-loid-beta neuronal toxins: a path forward for Alzheimer's disease immunother-apeutics. Alzheimers Res Ther. 2015; 6: 42 .

[32] Sakono M, Zako T Amyloid oligomers: formation and toxicity of A $\beta$ oligomers. FEBS J. 2010; 277: 1348-1358.

[33] Moreth J, Kroker KS, Schwanzar D, Schnack C Globular and proto-fibrillar $\mathrm{A} \beta$ aggregate simper neurotransmission by different mechanism. Bio-chem. 2013; 52: 1466-1476.

[34] Tamburri A, Dudilot A, Licea S, Bourgeois C, Boehm J NMDA-receptor activation but not ion flux is required for amyloid-beta induced syn-aptic depression. PLoS One. 2013; 8: e65350.

[35] Takamura A, Sato Y, Watabe D, Okamoto Y Sortilin is required for toxicaction of $A \beta$ oligomers $(\mathrm{A} \beta \mathrm{O})$ ): extracellular $\mathrm{A} \beta \mathrm{O}$ s trigger apoptosis, and intraneuronal $\mathrm{A} \beta \mathrm{O}$ s impair degradation pathways. Life Sci. 2012; 91: 1177-1186.

[36] Slack BE, Wurtman RJ Regulation of synthesis and metabolism of the amyloid precursor protein by extracellular signals. In: Research progress in Alzheimer's disease and dementia. M.-K. Sun, ed. 2007; 2: 1-25, Nova Science Publishers, Inc.

[37] Mattson MP Pathways towards and away from Alzheimer's disease. Nature. 2004; 430: 631-639.

[38] Inflammatory diseases - immunopathology, clinical and pharmaco-logical bases; in Khatami M (ed): Mehan S, Arora R, Sehgal V, Sharma D, Sharma G Dementia: A Complete Literature Review on Various Mechanisms Involved in Pathogenesis and an Intracerebroventricular StreptozotocinInduced Alzheimer's Disease. Rijeka, InTech. 2012: 3-19.

[39] Swardfager W, Lanctôt K, Rothenburg L A meta-analysis of cytokines in Alzheimer's disease. Biol Psychiatry. 2010; 68: 930-941. 
[40] Minati L, Edginton T, Bruzzone MG, Giaccone G Current concepts in Alzheimer's disease: a multidisciplinary review. Am J Alzheim Dis \& Other Dementia. 2009; 24: 95-121.

[41] Klafki HW, Staufenbiel M, Kornhuber J, Wiltfang J Therapeutic approaches to Alzheimer's disease. Brain. 2006; 129: $2840-2855$.

[42] Necula M, Kayed R, Milton S, Glabe CG Small molecule inhibitors of aggregation indicate that amyloid beta oligomerization and fibrillization pathways are independent and distinct. J Biol Chem. 2007; 282: 10311-10324.

[43] Birks J Cholinesterase inhibitors for Alzheimer's disease. Cochrane Database Syst Rev. 2006: CD005593.

[44] Gotti C, Riganti L, Vailati S, Clementi F Brain neuronal nicotinic receptors as new targets for drug discovery. Curr Pharm Des. 2006; 12: 407-428.

[45] Palmer GC Neuroprotection by NMDA receptor antagonists in a variety of neuropathologies. Curr Drug Targets. 2001; 2: 241-271.

[46] Ostrowski SM, Wilkinson BL, Golde TE, Landreth G. Statins reduce amyloid-beta production through inhibition of protein isoprenylation. J Biol Chem. 2007; 282: 26832-26844.

[47] Gray SL, Anderson ML, Crane PK, Breitner JC Antioxidant vitamin supplement use and risk of dementia or Alzheimer's disease in older adults. J Am Geriatr Soc. 2008; 56: 291-295.

[48] Dinarello CA Proinflammatory cytokines. Chest. 2000; 118: 503-508.

[49] Hunter CA, Timans J, Pisacane P Comparison of the effects of inter-leukin-1, interleukin-1 and interferon- inducing factor on the production of interferon- by natural killer. Eur J Immunol. 1997; 27: 2787-2792.

[50] Engelmann H, Novick D Two tumor necrosis factor-binding proteins purified from human urine. Evidence for immunological cross-reactivity with cell surface tumor necrosis factor receptors. J Biol Chem. 1990; 265: 1531-1536.

[51] Dinarello CA Anti-cytokine therapies in response to systemic infection. J Investigative Dermatology Symposium Proceedings. 2001; 6: 244-250.

[52] Huber TS, Gaines GS, Welborn MB Anticytokine therapies for acute inflammation and the systemic inflammatory response syndrome: IL-10 and ischemia/reperfusion injury as a new paradigm. Shock. 2000; 13: 425-434.

[53] Lee WH, Loo CY, Bedawy M, Luk F, Mason RS, Rohanizadeh R Curcumin and its derivatives: their application in neuropharmacology and neu-roscience in the 21st century. Curr Neuropharmacol. 2013; 11: 338-378.

[54] Shezad A, Lee YS (2013) Molecular mechanisms of curcumin action: signal transduction. Biofactors. 2013; 39: 27-36.

[55] Aggarwal BB, Kumar A, Bharti AC Anticancer potential of curcu-min: preclinical and clinical studies. Anticancer Res. 2003; 23: 363-398.

[56] Bharti AC, Takada Y, Aggarwal BB Curcumin (diferuloylmethane) inhibits receptor activator of NF- $\mathrm{BB}$ ligand-induced NF- $\mathrm{KB}$ activation in osteo-clast precursors and suppresses osteoclastogenesis. J Immunol. 2004; 172: 59405947.
[57] Teiten MN, Dicato M, Diederich V Curcumin as a regulator of epige-netic events. Mol Nutr Food Res. 2013; 57: 16191629 .

[58] Mithu VS, Sarkar B, Bhowmik D, Das AK, Chandrakesan M, Maity S, Madhu PK Curcumin alters the salt bridgecontaining turn region in amyloid (1-42) aggregates. The Journal of Biological Chemistry. 2014; 289: 11122-11131.

[59] Ishimura H, Kadoya R, Suzuki T, Murakawa T, Shulga S, Kurita N Specific interactions between amyloid- $\beta$ peptide and curcumin derivatives: $\mathrm{Ab}$ initio molecular simulations. Chemical Physics Letters. 2015; 633: 139-145.

[60] US Environmental Protection Agency. Health Effects Test Guidelines OPPTS 870. 100. Washington: US EPA; 2012.

[61] Vorobjova TM Role of limbic and reticular systems in self stimulation. Zhurnal Vysshei Nervnoi Deyatel'nosti imeni I. P. Pavlova. 1969; 19: 680-686.

[62] Bureš J, Petráň M, Zachar J Electrophysiological methods in biological research. Publishing House of the Czechoslovak Academy of Sciences, Prague. 1960: 528.

[63] Wang YJ, Pan MH, Cheng AL, Lin LI, Ho YS, Hsieh CY, Lin JK Stability of curcumin in buffer solutions and characterization of its degradation products. J Pharm Biomed Anal. 1997; 15: 1867-1876.

[64] Bakker JM, Kavelaars A, Kamphuis PJ, Cobelens PM, van Vugt $\mathrm{HH}$, van Bel F, Heijnen CJ Neonatal dexamethasone treatment increases suscepti-bility to experimental autoimmune disease in adult rats. J Immunol. 2000; 165: 5932-5937.

[65] Lowry OH, Rosebrough NJ, Farr AL, Randall RJ Protein measure-ment with Folin phenol reagent. J Biol Chem. 1951; 193: $265-275$.

[66] 66. Gasteiger E, Hoogland C, Gattiker A Duvaud S., Wilkins M. R., Ap-pel R. D., Bairoch A. Protein identification and analysis tools on the ExPASy server; (In) John M. Walker (ed): The Proteomics Protocols Handbook, Hu-mana Press. 2005: 571-607.

[67] Ashokan KV, Mundaganur DS, Mundaganur YD. Catalase: phylo-genetic characterization to explore protein cluster. J. Res. Bioinformatics. 2010; 1: 1-8.

[68] Sokolik VV Protein is coded in genome and synthesized in ribosomes as a structural template of a rotameric version sequence of peptide bound con-figuration. The International Moscow Conference on Computational Molecular Biology.

[69] Brooks BR, Brooks CL, Mackerell AD, Nilsson L CHARMM: the biomolecular simulation program. J Comput Chem. 2009; 30: $1545-1614$.

[70] Pronk S, Páll S, Schulz R, Larsson P, Bjelkmar P, Apostolov R, Shirts MR GROMACS 4.5: a high-throughput and highly parallel open source molecular simulation toolkit. Bioinformatics. 2013; 29: 845-854.

[71] Molecular modeling, 3rd Ed. Höltje H-D, Sippl W, Rognan D, Folkers G John Wiley \& Sons, Hoboken NJ 2008: 320.

[72] Protein ligand docking and virtual screening with GOLD. Cole J, Niessink J, Taylor R. In Virtual Screening in Drug Discovery (Eds. J. Alvarez, B. Shoichet), Taylor \& Francis CRC Press, Boca Raton, Florida, USA. 2005. 
[73] DeLano WL. The PyMOL molecular graphics system. DeLano Scien-tific, San Carlos, CA, USA 2002.

[74] Sokolik VV, Maltsev AV Cytokines neuroinflammatory reaction to $\beta$-amyloid 1-40 action in homoaggregatic and liposomal forms in rats. Biomed Chem. 2015; 9: 220-225.

[75] Stacklies W, Seifert C, Graeter F Implementation of force distribu-tion analysis for molecular dynamics simulations. BMC Bioinformatics. 2011; 101: 1-5.

[76] Venselaar H, Krieger E, Vriend G Homology modeling. Structural Bioinformatics. 2nd Edition. Wiley-Blackwell, Hoboken. 2009: 715-736.

[77] Samofalova DA, Karpov PA, Blume YB Bioinformatic comparison of human and higher plant phosphatomes. Citol Genet. 2015; 49: 207-219.

[78] Fändrich $M$, Schmidt $M$, Grigorieff $N$ Recent progress in understand-ing Alzheimer's $\beta$-amyloid structures. Trends Biochem Sci. 2011; 36: 338-345.

[79] Sadigh-Eteghad S, Sabermarouf B, Majdi A J Amyloid-Beta: A Crucial Factor in Alzheimer's Disease. Med Princ Pract. 2015; $24: 1-10$.

[80] Ridolfi E, Barone C, Scarpini E, Galimberti D The role of the innate immune system in Alzheimer's disease and frontotemporal lobar degeneration: an eye on microglia. Clin Dev Immunol. 2013: 939786.

[81] Boutajangout A, Wisniewski T The innate immune system in Alzheimer's disease. Int J Cell Biol. 2013: 576383.

[82] Combs CK, Karlo JC, Kao S-C $\beta$-Amyloid stimulation of microglia and monocytes results in TNF $\alpha$-dependent expression of inducible nitric oxide synthase and neuronal apoptosis. Journal of Neuroscience. 2001; 21: 1179-1188.

[83] Smith JA, Das A, Ray SK, Banik NL Role of proinflammatory cytokines released from microglia in neurodegenerative diseases. Brain Research Bulletin. 2012; 87: 10-20.

[84] Salminen A, Ojala J, Kauppinen A, Kaarniranta K, Suuronen $\mathrm{T}$ Inflammation in Alzheimer's disease: amyloid- $\beta$ oligomers trigger innate immunity defence via pattern recognition receptors. Progress in Neurobiology. 2009; 87: 181-194.

[85] Hasima N, Aggarwal BB Targeting proteasomal pathways by dietary curcumin for cancer prevention and treatment. Curr Med Chem. 2014; 21: 1583-1594.

[86] Aggarwal BB, Gupta SC, Sung B Curcumin: an orally bioavailable blocker of TNF and other pro-inflammatory biomarkers. Br J Pharmacol. 2013; 169: 1672-1692.
[87] Plummer SM, Holloway KA, Manson MM Inhibition of cyclo-oxygenase 2 expression in colon cells by the chemopreventive agent curcumin involves inhibition of NF$\kappa \mathrm{B}$ activation via the NIK/IKK signalling complex. Oncogene. 1999; 18: 6013-6020.

[88] Jobin CC, Bradham A, Russo MP, Juma B Curcumin blocks cyto-kine-mediated NF- $\kappa \mathrm{B}$ activation and proinflammatory gene expression by in-hibiting inhibitory factor IB kinase activity. J Immunol. 1999; 163: 3474-3483.

[89] Pan MH, Lin-Shiau SY, Lin JK Comparative studies on the suppres-sion of nitric oxide synthase by curcumin and its hydrogenated metabolites through down-regulation of IB kinase and NF- $\mathrm{KB}$ activation in macrophages. Biochem Pharmacol. 2000; 60: 1665-1676.

[90] Banerjee R. Effect of curcumin on the metal ion induced fibrillization of Amyloid- $\beta$ peptide. Spectrochimica Acta Part A: Molecular and Biomolecular Spectroscopy. 2014; 117: 798-800.

[91] Liu KN, Lai CM, Lee YT, Wang SN, Chen RP, Jan JS, Liu HS, Wang SS Curcumin's pre-incubation temperature affects its inhibitory potency toward amyloid fibrillation and fibrilinduced cytotoxicity of lysozyme. Biochimica et Biophysica Acta. 2012; 1820: 1774-1786.

[92] Reinke AA, Gestwicki JE Structure-activity relationships of amyloid beta-aggregation inhibitors based on curcumin: Influence of linker length and flexibility. Chemical Biology \& Drug Design. 2007; 70: 206-215.

[93] Yang FS, Lim GP, Begum AN, Ubeda OJ, Simmons MR Curcumin inhibits formation of amyloid beta oligomers and fibrils, binds plaques, and reduces amyloid in vivo. Journal of Biological Chemistry. 2005; 280: 5892-5901.

[94] Airoldi C, Zona C, Sironi E, Colombo L Curcumin derivatives as new ligands of A beta peptides. Journal of Biotechnology. 2011; 156: 317-324.

[95] Mourtas S, Canovi M, Zona C Curcumin-decorated nanoliposomes with very high affinity for amyloid- $\beta$ 1-42 peptide. Biomaterials. 2011; 32: 1635-1645.

[96] Taylor M, Moore S, Mourtas S, Niarakis A Effect of curcumin associated and lipid ligand-functionalized nanoliposomes on aggregation of the Alzheimer's A $\beta$ peptide. NanomedicineNanotechnology Biology and Medi-cine. 2011; 7: 541-550.

[97] Kozmon S, Tvaroska I Molecular dynamic studies of amyloidbeta interactions with curcumin and $\mathrm{Cu} 2+$ ions. Chemical Papers. 2015; 69: 1262-1276.

[98] Zhao LN, Chiu S-W, Benoit J, Chew LY, Mu YG The effect of cur-cumin on the stability of $A \beta$ dimers. The Journal of Physical Chemistry B. 2012; 116: 7428-7435. 